\title{
BCCiN4
}

\section{EXPERIMENTAL ASSESSMENT OF THE EFFECT OF PLASTICIZING AND AIR-ENTRAINING ADDITIVES ON MECHANICAL PROPERTIES OF REFRACTORY CEMENT COMPOSITE}

\author{
M. Jogl (1) and P. Reiterman ${ }^{(1)}$
}

(1) Experimental Centre, Faculty of Civil Engineering, Czech Technical University in Prague, Czech Republic

https://doi.org/10.21452/bccm4.2018.02.03

\begin{abstract}
This article is focusing on comparison of plasticizing and air-entraining additives and their effect on mechanical properties of composite based on aluminous cement. Achieved results supposed to help during the development of lightweight composite able to withstand temperatures over $1000^{\circ} \mathrm{C}$ and reduce heat transfer from a high temperature source, either by direct contact (conduction/convection) or via radiation. Operation at high temperature is of fundamental importance to many major sectors of industry, including material production and processing, chemical engineering, power generation and more. Objective is to achieve competitive performance with competitive life cycle costs. Maximum material efficiency and minimum manufacturing and operating costs are key factors in meeting this objective. Selection of a materials with sufficient economic conditions for a particular application must take account of many factors. For the purpose of this experiment, specimens were created from cement paste and different dosage of chopped carbon fibres. Experimental investigation underwent two series of samples different in the type of used additives. First series contains plasticizing additive, second series contains air-entraining additive. The purpose was to determine the different effect on the workability of fresh mixture, bulk density and mechanical properties. The strength of samples was measured after exposure to high temperatures of $600{ }^{\circ} \mathrm{C}$ and $1000{ }^{\circ} \mathrm{C}$. The residual properties were compared between each other and also to samples dried at the temperature of $105^{\circ} \mathrm{C}$. Obtained results revealed the level of influence of mentioned additives on the composition of studied refractory composite.
\end{abstract}

Keywords: Refractory composite, aluminous cement, high-thermal loading, superplasticizing additive, air-entraining additive.

\section{INTRODUCTION}

Refractory materials can be divided into several classes based on: chemical composition (acid, basic and special), method of implementation (shaped and unshaped), method of manufacture (fused and sintered), and porosity content (porous and dense) [1,2]. Refractories act as a thermal barrier between a hot medium and the wall of the containing vessel, they 
insure a strong physical protection, preventing the erosion of walls and they act as thermal insulation, insuring heat retention [3].

One of the most well-known techniques for the production of refractories and ceramics is the mixing of several components in the form of powder, formation of the mixture to the final shape and firing to the suitable temperature, where desired properties are attained [3]. For the formation of refractories can be used different bonding systems, such as ceramic bond, hydraulic bond and organic bond. Ceramic bond is a bond which comes into play typically at high temperatures through ceramization reactions, while hydraulic bond is ensured by the hydration of aluminous refractory cement added to the product [3].

Development of new composite materials is the worldwide extremely progressive branch of engineering activity. Composite materials are applied in many industries. Modern composites are often complicated system of selected binder modified by mineral additives and number of other chemical admixtures. Thanks today's technologies it is possible to reach required properties like high strength and good durability which is determined by extremely low level of water-cement ratio [4].

\section{MATERIALS}

The binder and its hydration products significantly control final properties, behavior and thermal resistance of composite [5] (SB). Silica composites based on Portland cement are not able to resist the effects of high temperatures, therefore a heat resistant mixtures in this experiment includes aluminous cement as binder of studied composites, allowing application for high temperatures more than $1000{ }^{\circ} \mathrm{C}$. Resistance of aluminous cement is directly affected by the content of $\mathrm{Al}_{2} \mathrm{O}_{3}$. Chemical properties of used aluminous cement is given in Table 1 . With those formulated cement is possible to reach satisfactory resistant to high temperature.

Table 1: Chemical composition of aluminous cement

\begin{tabular}{ccccccccc}
\hline Components & $\begin{array}{c}\mathrm{Al}_{2} \mathrm{O} \\
3\end{array}$ & $\mathrm{CaO}$ & $\mathrm{SiO}_{2}$ & $\begin{array}{c}\mathrm{Fe}_{2} \mathrm{O} \\
3\end{array}$ & $\mathrm{Na}_{2} \mathrm{O}$ & $\mathrm{MgO}$ & $\begin{array}{c}\mathrm{K}_{2} \\
\mathrm{O}\end{array}$ & $\begin{array}{c}\text { Specific } \\
\text { surface }\end{array}$ \\
\hline \% weight & 70.80 & 27.50 & 0.58 & 0.42 & 0.27 & 0.21 & 0.06 & $381 \mathrm{~m}^{2} / \mathrm{kg}$ \\
\hline
\end{tabular}

The main interest of this study was the effect of plasticizing and air-entraining additives on mixture's workability while in a plastic state and as mentioned on durability and mechanical properties of refractory cement composite before and after high thermal loading. For the creation of test samples was used commercial superplasticizer STACHEMENT 2000 (FM), based on polycarboxylate polymers, and air-entraining agent MICROPORAN 2 (LP), surfaceactive substance which is creating micro-size air bubbles. Both additives were provided by the company STACHEMA CZ s.r.o. The amount of additives in mixture was chosen according to the manufacturer's recommendations, $1 \%$ by weight of the cement dose. Their actions are only physical in fluidizing the mixture, made even with low water ratio.

Part of the research was also application of chopped carbon fibres and to analyze their degree of influence on workability of fresh mixture and residual properties of high temperature loaded composites. Fibre reinforced composite allows better durability in service than composite without fibres because of volume changes limiting and increasing of final tensile strength [6]. The material properties of the carbon fibre are presented in Table 2.

Table 2: Physical properties of carbon fibre

\begin{tabular}{lcccc}
\hline $\begin{array}{l}\text { Density } \\
\left(\mathrm{g} / \mathrm{cm}^{3}\right)\end{array}$ & $\begin{array}{c}\text { Length } \\
(\mathrm{mm})\end{array}$ & $\begin{array}{c}\text { Diameter } \\
(\mu \mathrm{m})\end{array}$ & $\begin{array}{c}\text { Tensile strength } \\
(\mathrm{GPa})\end{array}$ & $\begin{array}{c}\text { Tensile modulus } \\
(\mathrm{GPa})\end{array}$ \\
\hline
\end{tabular}




\begin{tabular}{lllll}
\hline 1.80 & 6 & 7 & 4.0 & 240 \\
\hline
\end{tabular}

\section{SPECIMEN PREPARATION AND TEST PROCEDURE}

For the experimental program were prepared prismatic specimens with the total dimensions of $40 \mathrm{~mm} \times 40 \mathrm{~mm} \times 160 \mathrm{~mm}$. Compositions of mixtures are shown in Table 3 .

Table 3: Composition of mixtures

\begin{tabular}{lrrrrrrrr}
\hline $\begin{array}{l}\text { Component } \\
{\left[\mathrm{kg} / \mathrm{m}^{3}\right]}\end{array}$ & \multicolumn{7}{c}{ Mixtures } \\
\cline { 2 - 8 } & AC & LP_0.0 & FM_0.0 & LP_0.5 & FM_0.5 & LP_1.0 & FM_1.0 \\
\hline Superplasticizer & 0 & 0 & 9 & 0 & 9 & 0 & 9 \\
Air-entrainer & 0 & 9 & 0 & 9 & 0 & 9 & 0 \\
Water & 224 & 224 & 224 & 224 & 224 & 224 & 224 \\
Aluminous cement & 900 & 900 & 900 & 900 & 900 & 900 & 720 \\
Carbon fibres & 0 & 0 & 0 & 9 & 9 & 18 & 18 \\
\hline
\end{tabular}

It is necessary to carry out a drying procedure and firing after cement composites maturity [7, 8]. All specimens were cured in humid environment for the 28 days, then dried at $105^{\circ} \mathrm{C}$ for 24 hours to eliminate initiating of cracks caused by the water vapor escaping. One third of specimens was tested immediately after the samples were dried out. Other two thirds were loaded by elevated high temperature.

The high-thermal loading was carried out in an electric kiln, which automatically increased the temperature by $10{ }^{\circ} \mathrm{C} / \mathrm{min}$ from ambient temperature to the desired values of $600{ }^{\circ} \mathrm{C}$ or $1000{ }^{\circ} \mathrm{C}$. Set temperature was then maintained automatically for 180 minutes and then the kiln cooled naturally.

The flexural and compressive strength of tested composites was investigated after the high-thermal loading was completed.

\section{RESULTS AND DISCUSSION}

Influence of composition changes was evaluated by the results of physical and mechanical testing. Flexural strength $\mathrm{f}_{\text {tm }}$ measurement was organized as a three point test with supports distance of $100 \mathrm{~mm}$ according and was calculated by help of the maximum reached force. The compressive strength test $\mathrm{f}_{\mathrm{cm}}$ was performed on two fragments left after flexural test. The area under compressive load ( $40 \mathrm{~mm} \times 40 \mathrm{~mm}$ ) has been demarcated by the loading device. Next to the mechanical properties, changes of bulk density $\rho$ were studied, since they are related to structural transformation during heating. All tests of mechanical properties were carried out according to the methodology described in European standard EN 196-1:2005 Methods of testing cement - Part1: Determination of strength.

All values of compressive strength, flexural strength and bulk density are presented after drying at $105{ }^{\circ} \mathrm{C}$ and after exposure to $600{ }^{\circ} \mathrm{C}$ and $1000{ }^{\circ} \mathrm{C}$. The summary results of the measured properties of the produced refractory composites are shown in Table 4. These values are means of three specimens (except of compressive strength $f_{c m}$, which is average from six performed tests). Table shows also an overview of the dependence of bulk density on temperature. 
Table 4: Summarized characteristic of experimental specimens.

\begin{tabular}{lcccccccccc}
\hline & \multicolumn{3}{c}{$\begin{array}{c}\text { Bulk Density } \\
\rho\left[\mathrm{kg} / \mathrm{m}^{3}\right]\end{array}$} & \multicolumn{3}{c}{$\begin{array}{c}\text { Flexural Strength } \\
\mathrm{f}_{\mathrm{tm}}[\mathrm{MPa}]\end{array}$} & \multicolumn{3}{c}{$\begin{array}{c}\text { Compressive Strength } \\
\mathrm{f}_{\mathrm{cm}}[\mathrm{MPa}]\end{array}$} \\
\cline { 2 - 11 } & $105^{\circ} \mathrm{C}$ & $600^{\circ} \mathrm{C}$ & $1000^{\circ} \mathrm{C}$ & $105^{\circ} \mathrm{C}$ & $600^{\circ} \mathrm{C}$ & $1000^{\circ} \mathrm{C}$ & $105^{\circ} \mathrm{C}$ & $600^{\circ} \mathrm{C}$ & $1000^{\circ} \mathrm{C}$ \\
\hline AC & 2110 & 1721 & 1695 & 6.2 & 1.9 & 1.6 & 123.0 & 99.8 & 64.9 \\
FM_0.0 & 2155 & 1787 & 1756 & 8.0 & 2.4 & 2.2 & 130.3 & 102.2 & 66.2 \\
LP_0.0 & 2110 & 1646 & 1585 & 4.6 & 1.4 & 1.1 & 121.0 & 98.6 & 64.3 \\
FM_0.5 & 2098 & 1747 & 1722 & 12.6 & 4.2 & 3.2 & 125.1 & 83.5 & 51.1 \\
LP_0.5 & 1954 & 1573 & 1536 & 8.2 & 2.6 & 2.2 & 118.2 & 92.1 & 59.4 \\
FM_1.0 & 2059 & 1679 & 1649 & 15.1 & 5.5 & 3.8 & 116.8 & 76.8 & 49.7 \\
LP_1.0 & 1905 & 1540 & 1485 & 12.0 & 3.2 & 2.8 & 114.1 & 82.3 & 51.5 \\
\hline
\end{tabular}

Flexural strength is predominantly affected by the dose of fibres. Reference set of specimens (without fibres) exhibits lower values of flexural strength than the specimens with added carbon fibres in doses of $0.5 \%$ and $1.0 \%$ by specimen's volume. Detailed results are shown in the Figure 1.

The results of compressive strength shown in Figure 2 are corresponding with the results of bulk density. There is obvious effect of fibres and air-entraining additive causing an increase of the air content in composites, which can have a negative impact on the adhesion of fibres and binding matrix. This fact can cause limits to their application and undesirable effects on mechanical properties. On the other side, fibers contribute to the limitation of volume changes during thermal loading and related crack formation [9]. This assumption is confirmed by the results of flexural strength.

\section{ㅁ $1000{ }^{\circ} \mathrm{C}$. $600{ }^{\circ} \mathrm{C}$ 圈 $105^{\circ} \mathrm{C}$}

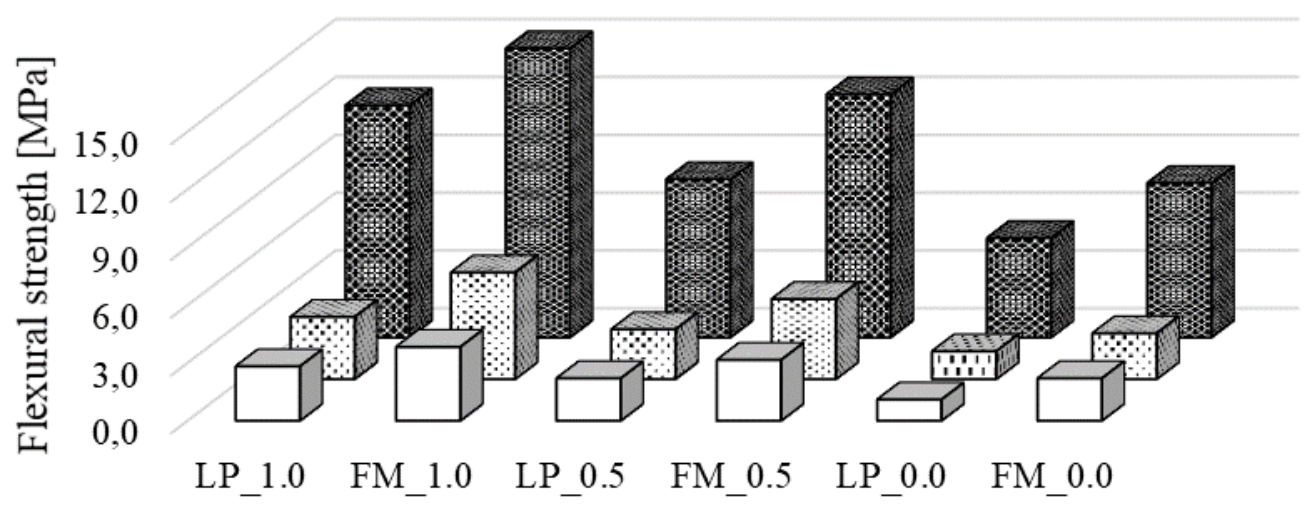

Figure 1: Relative values of flexural strength 


\section{ㅁ $1000{ }^{\circ} \mathrm{C}$ 曰600 ${ }^{\circ} \mathrm{C}$ 图 $105^{\circ} \mathrm{C}$}

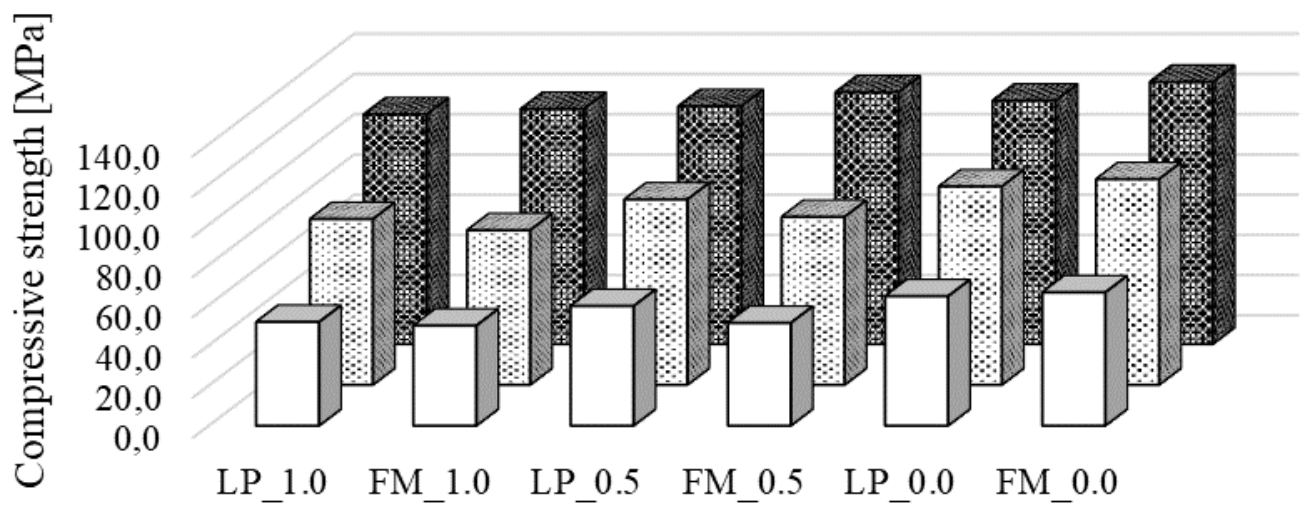

Figure 2: Relative values of compressive strength.

Figure 3 shows the values of bulk density of studied and thermally loaded composites. We can observe significant decline of the bulk density due to thermal loading which is caused by the mineralogical transformation and the loss of physically-bound water. Major role on the reduction of values of bulk density has the chemical decomposition of the hydration products and the content of siliceous components in the mixture. The bulk density values are also affected by the dosage of air-entraining additive. Thanks to the air-entrainer, micro-size air bubbles are created during mixing of the plastic composite and will stay as part of the hardened mixture.

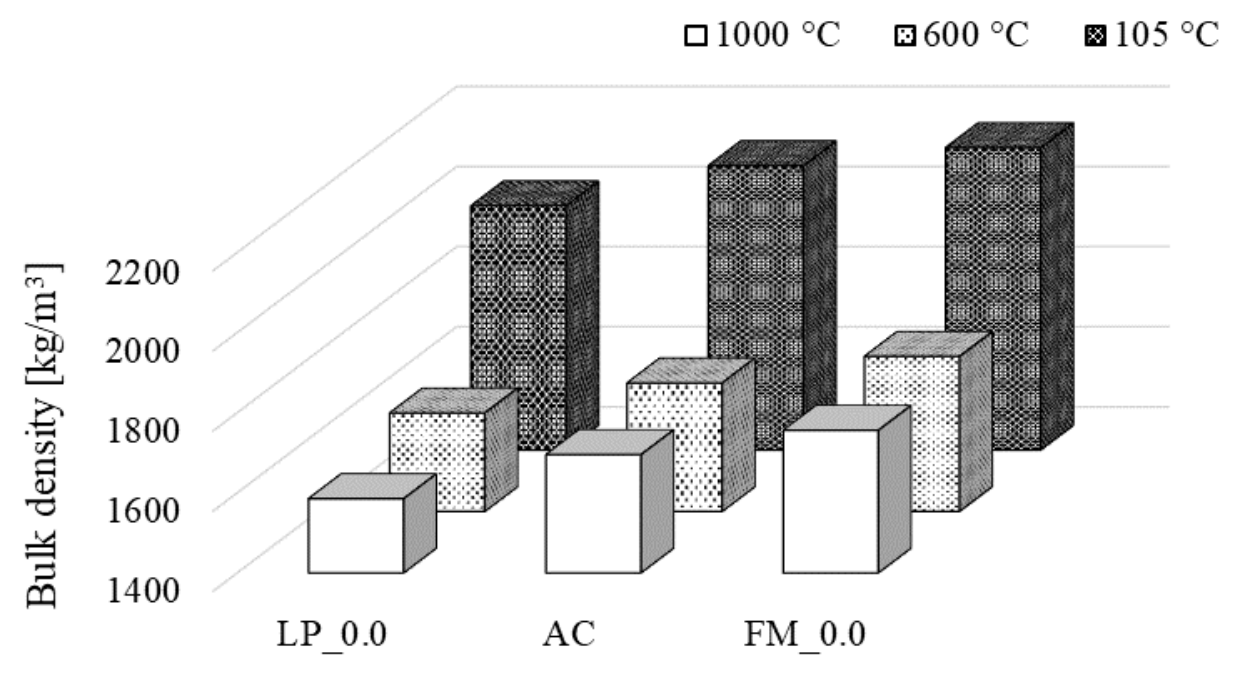

Figure 3: Relative values of bulk density.

\section{CONCLUSIONS}

Present paper contributes to the category of experimental research of special composites development. On the basis of performed experiments can be conclude that, in terms of mechanical properties, the most suitable values have been achieved by the composites with superplasticizing addtive. This fact arises in all cases of specimens, as in the case of fibre 
reinforced composites, as well in the case of composites without fibres. However, the amount of superplasticizer in designed mixture causes separation of water from cement mortar during the creation of specimens. Important is also evaluation of the bulk density results, where is evident the reduction of values due to air-entraining additive. But composites with air-entraining additive do not achieve such a level of workability as composites with the same amount of plasticizer.

The subsequent experiments will aim to increase the amount of the air-entraining additive and also to combine it with a reduced dose of superplasticizer, in order to improve the mixture's workability and further reduce the bulk density of hardened composites, while as much as possible preserve their properties after high temperature loading for the purpose of thermal barrier in an optional form between a hot medium and supporting structure.

\section{ACKNOWLEDGEMENTS}

The authors gratefully acknowledge the financial support provided by the project SGS16/199/OHK1/3T/11: Multicomponent binder systems for composite building materials.

\section{REFERENCES}

[1] Koňáková D., Hovorková V., Vejmelková E., Keppert M. and Černý R., 2014, 'Influence of Metashale as Cement Replacement on the Hygric Transport Properties of Concrete', Advanced Materials Research 1054 (2014) 188-193.

[2] Sadik Ch., Amrani I.-E. E., Albizane A., 'Recent advances in silica-alumina refractory: A review', Journal of Asian Ceramic Societies 2 (2006) 83-96.

[3] Katsavou I.D., Krokida M.K., Ziomas I. C., 'Determination of mechanical properties and thermal treatment behaviour of alumina-based refractories', Ceramics International 38 (2012) 5747-5756.

[4] Jogl M., Reiterman P., Holčapek O., Kot’átková J., 'Proposal of Fire Resistant Composites with Application of Lightweight Aggregate Liaver', Advanced Materials Research 1054 (2014) 43-47.

[5] M. Bruncvik, P. Stemberk, 'Explosion-resistant reinforced-concrete construction kit for shelter in extreme situations', Modelling, Measurement and Control 81 (2012) 34-49.

[6] Banthia N., 'Durability enhancements in concrete with fibre reinforcement', in Kraus R. N., Naik T. R., Clasisse P., Sadeghi P., editors, Proc. Int. Conf: Sustainable construction materials and technologies, 'Conventry, special papers proceedings', Pub UW Milwaukee CBU (2007) 209-219.

[7] G.A. Khoury, 'Effect of fire on concrete and concrete structures', Progress in Structural Engineering and Materials 2 (4) (2000) 429-447.

[8] R. Boris et al., 'Effect of holding temperature on properties of different types of heat-resistant concrete', Refractories and Industrial Ceramics 54 (2014) 397-400.

[9] D. Koňáková, V. Špedlová, M. Čáchová, E. Vejmelková, R. Černý, 'Influence of Basalt Fibres and Aggregates on the Thermal Expansion of Cement-Based Composites', Advanced Materials Research 1054 (2014) 17-21. 